\title{
Rol de la apoptosis en la sepsis
}

Pablo Andrés Vélez* 1,d; Evelyn Castro 1,d; Mario Montalvo 3,a,c; Santiago Aguayo 3,a; Gustavo Velarde 2,d; Fernando E. Jara González ${ }^{3, a}$; Jorge Luis Vélez ${ }^{3, a, b}$

\section{RESUMEN}

La sepsis es una entidad potencialmente mortal a causa de la disfunción multiorgánica que genera una respuesta alterada del huésped frente a la infección y que culmina, luego de varios procesos, en un estado de inmunosupresión. Hoy en día, existen varias estrategias de manejo de la sepsis para disminuir el impacto multisistémico y mejorar la supervivencia, pero ninguna ha mostrado una clara eficacia. Es por esto que los últimos estudios se centran en aclarar y buscar alternativas terapéuticas basadas en el análisis de la fisiopatología molecular, con la finalidad de entrar en un periodo tardío de inmunosupresión continúa, conocida también como parálisis inmune.

La apoptosis es un mecanismo molecular y fisiológico, cuya homeostasis es alterada en presencia de sepsis y que elimina células clave de la inmunidad innata y adaptativa, lo que conlleva a un mayor riesgo de infección secundaria, muchas veces fatal. Varios estudios post mortem han confirmado que la apoptosis de las células inmunes inducida por sepsis es un factor protagonista en la génesis de la inmunosupresión relacionada a la sepsis. Se cree que las estrategias terapéuticas dirigidas a regular la apoptosis podrían mejorar la supervivencia. Este es un artículo de revisión que describirá el rol fisiopatológico del fenómeno apoptótico en la sepsis y su repercusión en la evolución de esta entidad.

Palabras clave: Sepsis; Apoptosis; Inmunosupresión; Infecciones (DeCS: BIREME).

\section{The role of apoptosis in sepsis}

\section{ABSTRACT}

Sepsis is a life-threatening entity caused by a multiorgan dysfunction that generates a dysregulated host response to infection and, after several processes, results in immunosuppression. Today, there are several sepsis management strategies to reduce its multisystemic effect and improve survival, but none of them have shown clear efficacy. Therefore, latest studies focus on clarifying and seeking therapeutic alternatives based on the analysis of the molecular pathophysiology of sepsis, in order to enter a late period of continuous immunosuppression also known as immunoparalysis.

Apoptosis is a molecular and physiological mechanism, whose homeostasis is altered by the presence of sepsis. It causes the elimination of key cells of innate and adaptive immunity, which leads to an increased risk of-and often fatalsecondary infection. Several postmortem studies have confirmed that sepsis-induced immune cell apoptosis is a leading factor in the genesis of sepsis-related immunosuppression. It is believed that therapeutic strategies aimed at regulating apoptosis could improve survival. This review article describes the pathophysiological role of the apoptotic phenomenon in sepsis and its effect on the evolution of this entity.

Keywords: Sepsis; Apoptosis; Immunosuppression; Infections (Source: MeSH NLM).

1 Universidad Central del Ecuador. Quito, Ecuador.

2 Pontificia Universidad Católica del Ecuador. Quito, Ecuador.

3 Hospital Pablo Arturo Suárez. Quito, Ecuador.

a Médico especialista en Medicina Crítica.

b Magister en Investigación Clínica y Epidemiología.

c Magister en Epidemiología y Salud Colectiva.

d Médico Posgradista de Medicina Crítica y Terapia Intensiva.

* Autor corresponsal. 


\section{INTRODUCCIÓN}

La sepsis se ha convertido en un problema de salud pública en todo el mundo porque prolonga la estancia hospitalaria, aumenta los costos y ocasiona la muerte del paciente. Este panorama no ha mejorado, aunque se conoce mejor la fisiopatología; además, se han establecido diversas estrategias terapéuticas que no han mostrado una eficacia clara en cuanto a la supervivencia.

En el tratamiento de la sepsis, las medidas de apoyo recomendadas para lograr la sobrevida de un paciente son la terapia antibiótica, las estrategias de reanimación adecuadas y el soporte correcto para las fallas orgánicas ${ }^{(1)}$. Sin embargo, y aunque en las unidades de cuidados intensivos ( $\mathrm{UCl}$ ) los conceptos fisiopatológicos son más claros en relación al manejo del paciente crítico con sepsis, todavía pocas terapias son efectivas, lo que resulta en un aumento de incidencia del cuadro con un promedio de 31,5 millones de casos y 5,3 millones de muertes al año en el mundo, según los datos de países de altos recursos. La sepsis con disfunción orgánica múltiple posterior todavía es la principal causa de mortalidad en pacientes hospitalizados, con tendencia a incrementar las cifras en las próximas dos décadas; sin olvidar que en $\mathrm{UCl}$ es el factor asociado a mortalidad más común (valores por encima de $50 \%$ ). Esto ha llevado a buscar alternativas terapéuticas relacionadas con la fase de inmunosupresión dentro de procesos fisiopatológicos, y se ha planteado la hipótesis de que si el mecanismo de apoptosis de células se detiene, tanto en la inmunidad innata como en la adaptativa, se puede disminuir el daño multisistémico que culminaría en la muerte del paciente ${ }^{(2)}$.

\section{Estrategia de búsqueda}

Se realizó una búsqueda de información en las bases de datos MEDLINE, LILACS y WEB of SCIENCES, con las palabras clave en inglés (sepsis, apoptosis, immunosuppression, infection) y en español (sepsis, apoptosis, inmunosupresión, infección).

\section{NECROSIS, APOPTOSIS Y AUTOFAGIA}

Los mecanismos de muerte celular se clasifican en necrosis, apoptosis (muerte celular programada tipo 1) y autofagia (muerte celular programada tipo 2) que, a menudo, es reversible. En la necrosis, las células presentan un citoplasma inflamado con estructuras orgánicas desorganizadas, membranas rotas y una apariencia lítica en sus núcleos (cariolisis). La célula apoptótica muestra condensación de la cromatina, con posterior conversión a núcleos fragmentados (cariorrexis) y la formación de cuerpos apoptóticos, todo ello con una membrana plasmática y orgánulos intactos. Estas características difieren de la autofagia, proceso en el cual la célula degrada sus propios componentes para reciclar o eliminar el contenido citoplasmático excesivo, lo que conduce a la formación de autofagosomas, vesículas de gran tamaño, de doble membrana que engloban el citosol y los orgánulos. Una vez que la capacidad autofágica de una célula se ve afectada, se produce su apoptosis ${ }^{(3)}$.

\section{APOPTOSIS}

La apoptosis se define como la muerte celular programada. Es el proceso por el cual la célula activa enzimas capaces de degradar su propio ADN y todos sus componentes proteicos nucleares y citoplasmáticos. Se inicia con el desprendimiento de pequeños fragmentos de células que ya han realizado apoptosis, con la particularidad de que la membrana celular aún permanece estructuralmente intacta. Sin embargo, la célula sufre modificaciones moleculares que la convierten en un sitio de acción llamativo para fagocitos encargados de su eliminación total antes de que la liberación de sus componentes origine una respuesta inflamatoria en el huésped. La necrosis difiere de la apoptosis en que se caracteriza por una pérdida total de la integridad estructural de la membrana, con liberación de todos sus componentes, aunque es importante resaltar que estos dos fenómenos pueden coexistir en algunos procesos patológicos, cuando una apoptosis inducida se transforma en necrosis ${ }^{(4)}$.

\section{Apoptosis en situaciones fisiológicas}

Este proceso celular es necesario y normal en el organismo para de eliminar las células que han cumplido su vida útil, pero también para aquellas que representan un potencial daño. Así mismo, se convierte en un proceso patológico cuando el intento de reparación celular fracasa, sobre todo en situaciones de daño irreversible a nivel del ADN o de las proteínas celulares, donde es inevitable la eliminación celular.

Dentro de lo fisiológico podemos nombrar a la apoptosis como protagonista en eventos como 1) el cambio de tejidos en situaciones de embriogénesis; 2) la privación hormonal con la consecuente involución del tejido glandular; 3) la degradación del tejido endometrial durante el ciclo menstrual; 4) la regresión mamaria una vez culminado el periodo de lactancia; 5) la eliminación de poblaciones celulares en proliferación como los epitelios de las criptas intestinales. En cuanto a la inmunidad, el proceso apoptótico se lleva a cabo en los neutrófilos y linfocitos, una vez que han perdido la capacidad de generar señales de supervivencia posterior a una respuesta inflamatoria aguda. La apoptosis también ocurre para la eliminar los linfocitos autorreactivos con la finalidad de limitar la respuesta autoinmune $\mathrm{y}$, por último, el conocido mecanismo de defensa de los linfocitos citotóxicos para destruir células infectadas por virus y células neoplásicas ${ }^{(5)}$.

\section{Apoptosis en situaciones patológicas}

Las células con alteraciones genéticas, o que han sufrido alguna lesión genética sin oportunidad de reparación, son eliminadas por el proceso de apoptosis mediante 
reacciones que causan un mínimo daño en el huésped. En ciertas situaciones en las cuales los factores de reparación no pueden remediar el daño, como el uso de fármacos citotóxicos anticancerosos, radiación o producción de radicales libres que pueden dañar el ADN directa o indirectamente, se desencadena la apoptosis si la lesión es leve y si es más severa, ocurre la necrosis. La apoptosis de las células cancerosas es un ejemplo muy claro en el que se basa el mecanismo de acción de algunos agentes quimioterápicos que actúan dañando el ADN.

Otros mecanismos que inducen apoptosis son la acumulación de proteínas mal plegadas por mutaciones genéticas que causan estrés del retículo endoplásmico, la lesión celular causada por infecciones, predominantemente víricas, y la lesión obstructiva de conductos de órganos como riñón, páncreas y glándulas parótidas ${ }^{(6)}$.

\section{Mecanismos de la apoptosis}

La fisiopatología de la apoptosis se basa en un mecanismo enzimático fundamental que tiene como protagonistas principales a las caspasas. Estas son proteasas de cisteína que median la ruptura de otras proteínas, a nivel del residuo de aspartato. Para que estas enzimas se activen, convergen dos vías, conocidas como la vía mitocondrial y la vía de los receptores de muerte, que pueden interactuar entre ellas, pero son inducidas por distintas condiciones (Figuras 1 y 2).
Vía mitocondrial (intrínseca) de la apoptosis

Dentro de las mitocondrias existen diversas proteínas que pueden inducir apoptosis, entre ellas destaca el citocromo c y otras que neutralizan los inhibidores endógenos de la apoptosis. La permeabilidad mitocondrial, que determina la vida o muerte de la célula, está dirigida por un complejo de más de 20 proteínas tanto pro como antiapoptóticas, conocido como Bcl-2 (B-cell lymphoma 2, por sus siglas en inglés). Cuando las células son privadas de factores de crecimiento u otras señales de supervivencia, o están expuestas a injuria en el ADN, o acumulan una gran cantidad de proteínas mal plegadas, se activan sensores moleculares que forman parte de la familia de $\mathrm{Bcl}-2$, conocidos como $\mathrm{BH} 3$, que se encargan de inhibir a las moléculas antiapoptóticas Bcl-2 y Bcl-xL. Además, activan a dos factores proapoptóticos de la misma familia, conocidos como Bax y Bak, los cuales forman canales que se insertan en la membrana de la mitocondria, y logran que el citocromo c y otras proteínas mitocondriales salgan hacia el citoplasma. De esta manera, la caspasa 9 se activa ${ }^{(7)}$. Con ayuda de otras proteínas provenientes de las mitocondrias, ocurre el bloqueo de las actividades de los antagonistas de las caspasas, cuyo rol es inhibir de manera fisiológica el proceso de apoptosis. Con toda esta serie de sucesos, el resultado es la activación de la cascada de las caspasas, que culmina en la fragmentación del núcleo celular ${ }^{(5,8,9)}$ (Figura 1).

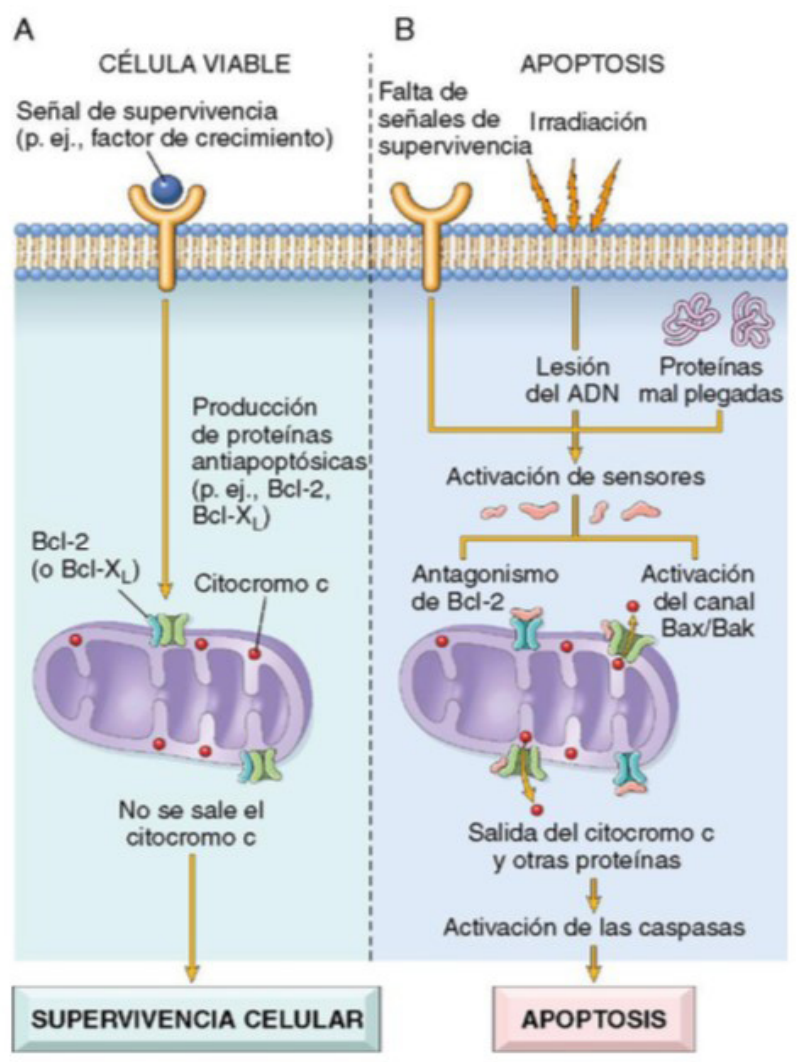

Horiz Med (Lima) 2020; 20(4):e1219 
Figura 1. Vía mitocondrial de la apoptosis. A. En una célula viable, los miembros anti-apoptóticos de la familia Bcl-2 impiden la salida de las proteínas mitocondriales. B. Distintos estímulos lesivos, activan los sensores citoplásmicos y reducen la producción de estas proteínas antiapoptóticas con aumento de la cantidad de proteínas apoptóticas, lo que se traduce en la extravasación de una serie de proteínas que activan las caspasas: primero las iniciadoras y luego las ejecutoras; estas enzimas condicionan la fragmentación del núcleo y, en último término, de la célula. Tomado de Mitchell R, Kumar V, Abbas A, Aster J. Robbins y Cotran - Patología estructural y funcional. 9a. Barcelona, España: Elsevier; $2017^{(5)}$

\section{Vía de los receptores de muerte (extrínseca) de la apoptosis}

Esta vía se caracteriza por eliminar los linfocitos autorreactivos y destruir las células diana por los linfocitos citotóxicos. Destacan las moléculas de superficie denominadas receptores de muerte, la mayoría de las cuales son miembros de la familia de receptores del factor de necrosis tumoral (TNF, del inglés tumoral necrosis factor) que incluye el tipo TNF-I y el Fas. Este último, se encuentra unido a su respectivo ligando, el Fas-ligando
(FasL), que es una proteína de membrana expresada sobre todo en linfocitos $T$ activados. Cuando estos linfocitos $T$ reconocen dianas que expresan Fas, las moléculas Fas se entrecruzan por FasL, y se juntan a una clase de proteínas adaptadoras para su unión a la caspasa 8 . Se ha considerado que esta vía alimenta a la vía intrínseca, de tal manera que resulta letal para la célula. Cabe mencionar que algunas formas virales producen un homólogo de antagonista de las caspasas denominado FLIP, con el que logran mantener vivas a las células infectadas.

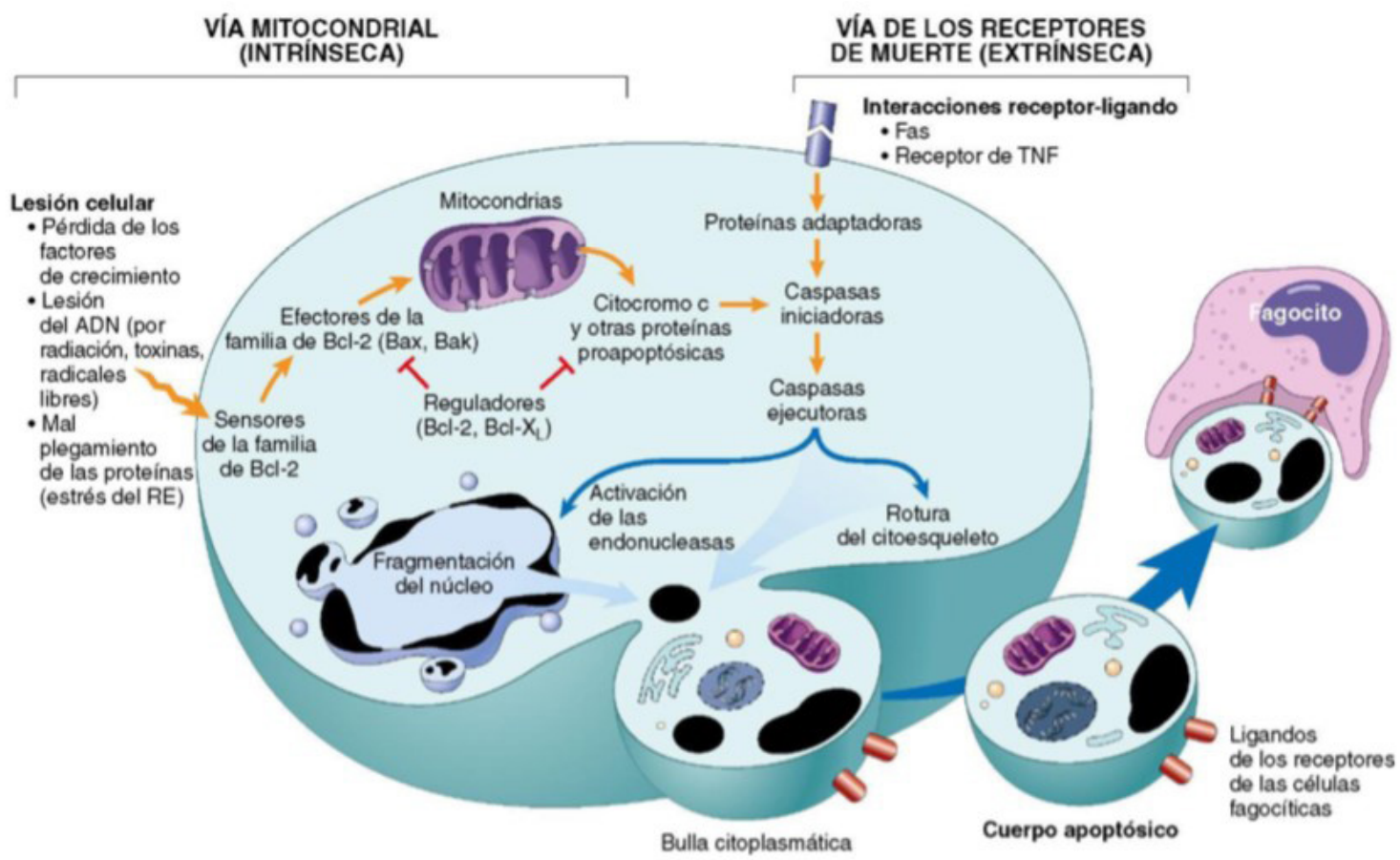

Figura 2. Vías y mecanismos implicados en la apoptosis celular. Tomado de Mitchell R, Kumar V, Abbas A, Aster J. Robbins y Cotran. Patología estructural y funcional. 9a. Barcelona, España: Elsevier; $2017^{(5)}$

\section{Vía inducida por el estrés del retículo endoplásmico}

Es la menos conocida de las vías que activan la muerte celular programada. En esta secuencia, la célula desencadena vías de señalización de proteínas desplegadas en respuesta a la liberación de especies reactivas de oxígeno (ERO) o al estrés del retículo endoplásmico, para hacer frente a dichas condiciones y para monitorear la capacidad de plegamiento de proteínas del retículo endoplásmico. De esta manera, la célula regula varios aspectos claves del metabolismo celular para desarrollar o no la apoptosis ${ }^{(10,11)}$.

\section{Eliminación de las células apoptóticas}

La fosfatidilserina es un fosfolípido ubicado en la cara interna de la membrana plasmática de las células normales. Sin embargo, en las células apoptóticas, este fosfolípido se exterioriza para ser reconocido por 
macrófagos tisulares, lo que permite, mediante señales de eliminación apoptótica (find-me, eat-me), la fagocitosis de los cuerpos apoptóticos. Como consecuencia de la apoptosis, las células muertas secretan factores solubles que reclutan a los fagocitos. De este modo, las células muertas son eliminadas rápidamente, y se evita que liberen sus contenidos celulares, responsables de procesos inflamatorios ${ }^{(12,13)}$.

Mecanismos y consecuencias de la apoptosis en la sepsis

Después de la fase inicial de la sepsis, la inmunosupresión se convierte en el resultado de mecanismos apoptóticos que intervienen en la selección de poblaciones de células inmunes, pero también en su pérdida. Su persistencia puede comprometer la respuesta normal del huésped ante antígenos invasores. La apoptosis de estas células ha sido reconocida como un elemento muy importante en la fisiopatología de la sepsis y en sus complicaciones. Por ello, en esta entidad es característico encontrar una función inmune deteriorada por una apoptosis generalizada en los órganos de la inmunidad innata (timo o bazo) y también en células como neutrófilos, macrófagos, células dendríticas y varias grupos de linfocitos ${ }^{(4)}$.

Aún no están claras las vías que llevan a cabo este proceso; sin embargo, se cree que ocurre en primera instancia por la muerte de las células dendríticas (CD), células presentadoras de antígenos, lo que desencadena el comienzo y posterior avance de la parálisis inmune, lo cual resulta en un deterioro marcado de la inmunidad innata y de la adaptativa.

En los macrófagos, la acción de la caspasa 8 ocasiona la disminución de citocinas proinflamatorias como la interleucina 6 (IL-6) y el TNF-a, y el huésped entra en un estado de inmunosupresión que, a su vez, activa factores antiinflamatorios como la interleucina 10 (IL-10) y el factor de crecimiento transformante beta (TGF-B), lo que promueve la apoptosis ${ }^{(14)}$ (Figura 3 ).

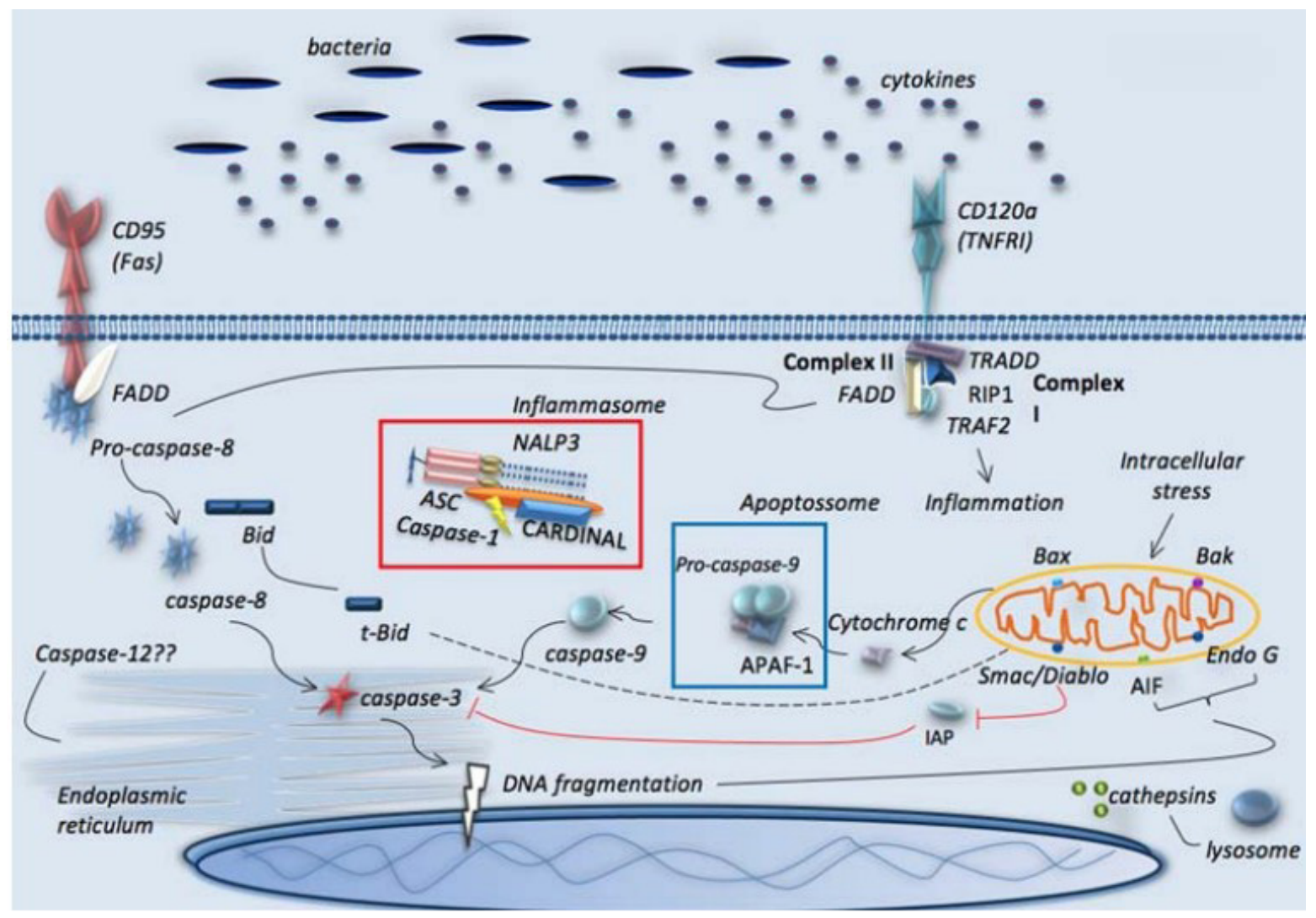

Figura 3. Vías de apoptosis en sepsis. Representación de las vías clásicas de receptores de muerte, mitocondriales y retículo endoplásmico. Se ilustran también los inflamasomas y las vías lisosomales. Tomado de Pinheiro da Silva F, Nizet V. Cell death during sepsis: Integration of disintegration in the inflammatory response to overwhelming infection. Apoptosis. 1 de abril de 2009;14(4):509-21 (3) 


\section{Apoptosis de células inmunes}

El agotamiento de células inmunes juega un papel crucial en la inmunosupresión inducida por la sepsis. La alteración de la inmunidad del huésped se genera por procesos como la anergia, la reactivación de la infección latente, la susceptibilidad a infecciones secundarias, y el mecanismo más importante: el daño apoptótico directo en células inmunes de la microvasculatura, lo que contribuye a una infección secundaria y a la supresión causante de disfunción multiorgánica refractaria y fatal (15-19). A continuación, se describe el proceso apoptótico de células inmunes (Figura 4).

\section{Apoptosis de neutrófilos}

Los neutrófilos son células inflamatorias de la primera línea de defensa contra los patógenos. Poseen un gran potencial oxidativo y proteolítico, cuya alteración tiene gran impacto en la defensa del huésped. En condiciones fisiológicas, los neutrófilos son granulocitos de corta duración, cuya muerte en 24 horas depende de las caspasas y que expresan moléculas proapoptóticas de la familia $\mathrm{Bcl}-2$, como Bad, Bax, Bid, Bak y Bik ${ }^{(20,21)}$. Sin embargo, en la etapa inicial de la sepsis, el nivel de neutrófilos aumenta rápidamente debido a su apoptosis tardía; a esto se suma la liberación de neutrófilos inmaduros desde la médula ósea, lo que conduce a inflamación persistente ya un agravamiento orgánico que está influenciado directamente por la infiltración neutrofílica hacia los tejidos. Además, están implicadas proteínas antiapoptóticas como la cinasa dependiente de ciclina, perteneciente a la familia Bcl-2, que regula la expresión de la proteína antiapoptótica Mcl-1, lo que prolonga la vida de los neutrófilos ${ }^{(22,23)}$.

\section{Apoptosis de macrófagos}

Los macrófagos son células clave para iniciar, mantener y resolver los procesos inflamatorios e infecciosos del huésped. En relación a los mecanismos de apoptosis de estas células, se sabe que el proceso de eliminación celular, cuando es excesivo, conduce a la inmunosupresión $y$, en consecuencia, aumenta el riesgo de infección por gérmenes oportunistas. Muchas vías de señalización celular comandadas por acción de citoquinas promueven o inhiben los procesos inflamatorios y participan en la apoptosis activa dentro del marco de la sepsis. Las evidencias indican que algunas citocinas (como IL-1 o IL-6) provocan inflamación pero inhiben la apoptosis; mientras que otras, como TNF-a y HMGB1 (High Mobility Group B1, por sus siglas en inglés), se caracterizan por ser inductoras del mencionado proceso de eliminación celular ${ }^{(19,24)}$.

En este contexto los macrófagos pueden realizar dos polarizaciones: $M 1$ (expresión de citocinas inflamatorias) y M2 (expresión de citocinas antiinflamatorias) ${ }^{(25)}$. La apoptosis de macrófagos conduce al desequilibrio de las citocinas pro y antiinflamatorias, lo que resulta en la polarización de macrófagos a un fenotipo $M 2$, la liberación de citoquinas antiinflamatorias predomina como IL-10 e
IL-1 receptor antagonista (IL-1ra) y la disminución de las citocinas proinflamatorias, con el efecto subsecuente en la inmunidad del huésped. Un estudio prospectivo encontró que la estimulación con HMGB1 se podría relacionar con la inducción de la apoptosis de los macrófagos peritoneales de ratón, con efecto dosis y tiempo dependiente ${ }^{(24,26,27)}$, lo que hace de este proceso una de las dianas terapéuticas en la sepsis.

\section{Apoptosis de células dendríticas (CD)}

En la respuesta inmune innata y en la adaptativa, las CD son células clave que, al reconocer señales moleculares de peligro, tienen la función de presentar los antígenos a los linfocitos T vírgenes. Una vez que han sido activadas mediante estímulos derivados de procesos de inflamación, las células dendríticas convencionales (CDC) maduran y migran hacia las zonas de linfocitos T en órganos linfoides, donde cumplen su función principal ya mencionada (28). Estas CDC, luego de adquirir su capacidad efectora y de experimentar procesos de diferenciación terminal, mueren por apoptosis.

Como sucede con los macrófagos, se ha observado que la apoptosis de CD también está asociada con la inmunosupresión debida a varias condiciones patológicas e infecciosas. El mecanismo de apoptosis de CD mediante lipopolisacáridos (LPS) está caracterizado por la activación de isoformas C2 y c3 del factor nuclear de las células T activadas (NFAT) mediado por CD14 ${ }^{(28)}$. Se ha descubierto que la exposición de las DC a LPS induce la activación de las quinasas de la familia Src y la fosfolipasa $C$ y2, una afluencia de calcio extracelular $\left(\mathrm{Ca}^{2+}\right)$ y translocación nuclear NFAT dependiente de calcineurina ${ }^{(28,29)}$. Además, hay otros mecanismos moleculares que conducen a la apoptosis de CD después de la activación.

El extenso proceso de la apoptosis mediada por la vía de la caspasa-3 de las CD puede también conducir a la inmunosupresión que se observa en los modelos de sepsis en humanos y en ratones, mientras que su supresión resulta en resistencia a endotoxinas y depresión inmune ${ }^{(30,31)}$.

\section{Apoptosis de linfocitos $B$}

Los linfocitos B son células de vital importancia para las respuestas inmunes innata y adaptativa. En circunstancias fisiológicas, las células B efectoras activadas podrían diferenciarse en células plasmáticas o células $B$ de memoria, promoviendo la respuesta inmune humoral y actuando como células presentadoras de antígeno que interactúan con las células $T$ cooperadoras. Las funciones de las células $B$ se limitan a producir los anticuerpos y desarrollar células B plasmáticas de memoria ${ }^{\left({ }^{(3)} \text {. }\right.}$

Durante la sepsis, sobre todo en la etapa temprana, la apoptosis deteriora las células $B{ }^{(33)}$,lo que junto al agotamiento transitorio de células $B$ de memoria (producida 
por endotoxemia) debilita la inmunidad ${ }^{(34)}$. Existe evidencia basada en la administración de un inhibidor selectivo de la histona desacetilasa 6 que mostró restablecer el porcentaje de linfocitos B además de incrementar el porcentaje de células inmunes innatas y macrófagos ${ }^{(35)}$.

\section{Apoptosis de linfocitos NK}

Los linfocitos NK (del inglés, natural killer cells) pertenecen al linaje linfoide; se diferencian de los linfocitos $T$ en que no expresan CD3 en la membrana celular y no sufren el proceso de selección a nivel del timo. Estas células son importantes en la respuesta celular de la inmunidad innata, y participan a través de mecanismos citotóxicos mediados por moléculas preformadas como la perforina y fragmentinas; además, secretan citocinas como interferones tipos I y II. Las células NK cumplen su función por medio de una serie de receptores específicos conocidos como NKR (natural killer receptors). En los humanos, los NKR más estudiados son el CD94 y la familia de la molécula NKG2. Estos receptores reconocen moléculas de clase I del complejo mayor de histocompatibilidad (MHC) en la superficie de las células. La ausencia o baja expresión del MHC de clase I inicia una serie de eventos para activar las células NK que terminan con la lisis de la célula blanco. En condiciones normales, las células NK pueden inducir una respuesta inmune innata rápida y no específica contra bacterias intracelulares, piógenas, hongos, protozoos y virus. La característica más importante en estas células es que su apoptosis acelerada conduce a la disminución de su población circulante ${ }^{(36,37)}$ en un lapso de varias semanas durante la sepsis ${ }^{(38)}$. Las subpoblaciones de células $\mathrm{CD} 6^{\text {hi }}$ y CD56 $^{\text {lo }}$ también están alteradas, y se asocian a una mayor mortalidad en pacientes con sepsis ${ }^{(39,40)}$. Una característica muy importante de la NK es que poseen una función citotóxica, la cual disminuye notablemente ante la apoptosis lo que provoca una inmunosupresión marcada con incremento del riesgo de infección secundaria.

Contrarrestar la pérdida de respuestas inmunes en la sepsis se ha convertido en un objetivo terapéutico potencial para la intervención terapéutica ${ }^{(41,42)}$. Por ello, la inmunoterapia basada en el bloqueo de PD-1 / ligando de muerte celular programada (PD-L1) se puede emplear durante la inmunosupresión asociada a la sepsis, como consecuencia de la pérdida de la función protectora de las células NK ${ }^{(43,44)}$.

(A) Innate immune cells

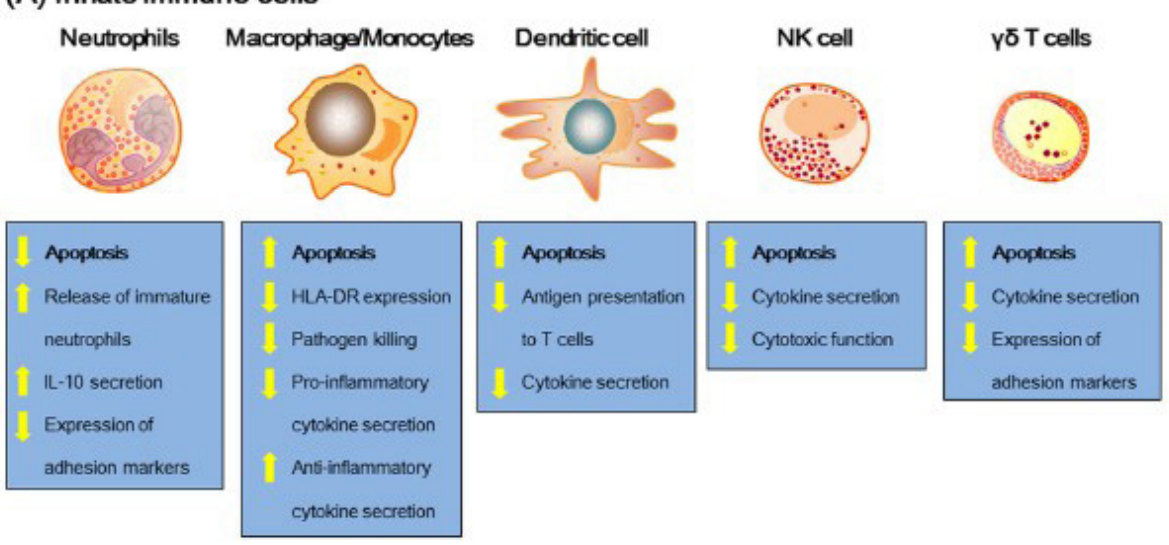

(B) Adaptive immune cells
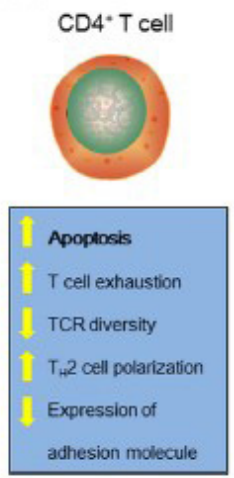
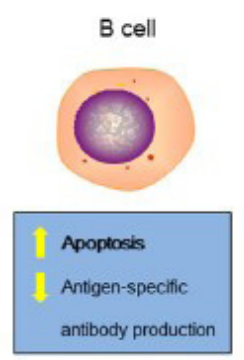

Treg cell
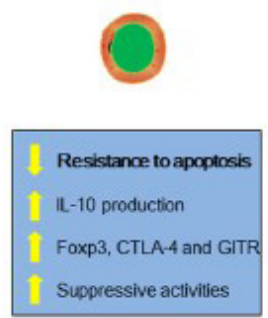

Figura 4. Alteraciones características de las células inmunes innatas y adaptativas en la sepsis. Tomado de Cao C, Yu M, Chai Y. Pathological alteration and therapeutic implications of sepsis-induced immune cell apoptosis. Cell Death Dis. octubre de 2019;10(10):782 (2) 


\section{Apoptosis de linfocitos $T$}

La función de los linfocitos T es la defensa adaptativa del organismo contra los patógenos invasores y las células neoplásicas, a partir del reconocimiento de los antígenos con un receptor altamente específico expresado en su membrana. Este reconocimiento estimula una serie de eventos que conducen a la activación, diferenciación y proliferación linfocitaria. Los linfocitos activados pueden tener acción efectora o transformarse en linfocitos de memoria, los cuales reaccionan rápidamente contra el antígeno en el caso de reexposición ${ }^{(45)}$.

Una gran cantidad de linfocitos T de memoria está en los tejidos de barrera (piel, pulmón, tracto gastrointestinal, peritoneo, tracto reproductivo y médula ósea) ${ }^{(46)}$ y tiene la función de proporcionar una respuesta inmediata al reingreso o reactivación de patógenos ${ }^{(47)}$. Los pacientes con sepsis muestran una respuesta inmunológica deteriorada que contribuye a la letalidad del trastorno. Varias investigaciones clínicas han demostrado que la apoptosis y la supresión inmune son actores importantes en la fisiopatología de la sepsis y que también están estrechamente entrelazados. El estudio de algunas de las proteínas involucradas en la apoptosis ha intentado explicar este intrincado proceso ${ }^{(48)}$.

La apoptosis de los linfocitos T está regulada por una red de vías de señalización que controla la expresión y supresión de moléculas clave ${ }^{\left({ }^{49}\right)}$. Según Weber et al. ${ }^{(50)}$, en la vía intrínseca los mecanismos implicados son el aumento en la proteína proapoptótica Bim y una disminución en el nivel de moléculas antiapoptóticas ( $\mathrm{Bcl}-2$ y $\mathrm{Bcl}-\mathrm{xL}$ ) en los linfocitos de pacientes con sepsis.

El estudio de Hotchkiss en ratones transgénicos mostró que el la supervivencia aumentó de manera notable debido a la sobreexpresión de $\mathrm{Bcl}-2{ }^{(51)}$. En la vía extrínseca, el papel de la caspasa 8 es fundamental en la regulación de la apoptosis debido a su función en la actividad de NF-kB. En estudios experimentales con animales, la reducción de la caspasa-8 disminuyó la apoptosis de los linfocitos Ty además mostró mejoría en la supervivencia en ratones sépticos. Sin embargo, ninguna de las dos vías ha demostrado ser dominante.

Es así que en el estudio de Hotchkiss, realizado en ratones transgénicos, el aumento de la supervivencia fue notable a través de la sobreexpresión de $\mathrm{Bcl}-2{ }^{(51)}$. En lo que a la vía extrínseca respecta, el papel de la caspasa 8 es fundamental en la regulación de la apoptosis por su función en la actividad de NF-KB, en estudios experimentales con animales, la disminución de la caspasa-8 disminuyó la apoptosis de los linfocitos Ty además mostró mejoría en la supervivencia en ratones sépticos. Sin embargo, ninguna de las dos vías ha demostrado ser dominante.
Entre los mecanismos moleculares por los cuales la apoptosis de los linfocitos continua después de la sepsis, se ha descrito la ruta TRAIL (ligando inductor de la apoptosis relacionado con el TNFa). Gurung et al. (2012) encontraron que la incapacidad de instauración de la hipersensibilidad de tipo retardado durante la sepsis dependía de la supresión inmune activa mediada por TRAIL. En este estudio, la neutralización de esta ruta consiguió regenerar la respuesta de las células T CD8 antígeno-específicas ${ }^{(52)}$. En consecuencia, la neutralización de TRAIL (53) podría ser uno de los objetivos terapéuticos potenciales para regular la inmunidad celular, acortar el curso prolongado y disminuir las complicaciones infecciosas a largo plazo que a menudo ocurren en los pacientes sépticos.

\section{Perspectivas clínicas y enfoque traslacional}

Detener el agotamiento de células inmunes inducido por apoptosis durante la sepsis es un objetivo terapéutico para trabajos experimentales realizados, en su mayoría, en animales. Las terapias inmunoadyuvantes se han empleado para prevenir la apoptosis linfocitaria mediante sobreexpresión de Bcl-2 y se logró mejorar la supervivencia. De igual manera, IL-7 y anti-PD-L1 tienen efectos potentes para prevenir la apoptosis de linfocitos. En este contexto, la administración de IL-7 es una terapia atractiva en la sepsis, porque bloquea la apoptosis inducida de las células efectoras inmunes y aumenta el IFN- $\gamma$, citocina clave para llevar a cabo una respuesta inmune adaptativa eficaz del huésped contra los patógenos invasores ${ }^{(2)}$.

Respecto a las moléculas proapoptóticas, se ha sugerido que, en modelos animales, la supresión de Bim puede resultar una estrategia prometedora. Bim es el único componente de la cascada de apoptosis cuya eliminación induce una protección completa contra la muerte celular apoptótica en ratones sépticos ${ }^{(54)}$.

\section{CONCLUSIONES}

La sepsis y el choque séptico son los cuadros con mayor incidencia en $\mathrm{UCl}$. El tratamiento de ambos está fundamentado en el inicio temprano de la terapia antibiótica y en una reanimación por objetivos; estas conductas se han convertido en las mejores estrategias terapéuticas para evitar las complicaciones. Pese a esto, la mortalidad sigue siendo alta, lo que ha llevado a buscar otras opciones terapéuticas basadas en el conocimiento fisiopatológico de la enfermedad.

El conocimiento fisiopatológico de la sepsis se ha profundizado aún más. Actualmente, el componente y la respuesta inmunológica son conocidos, con lo cual, ya se tiene un concepto claro : que la alteración en vías y componentes de la inmunidad innata y adaptativa juega un rol clave en la progresión de la enfermedad. 
La apoptosis es un proceso molecular y fisiológico muy necesario para mantener la homeostasis celular. Su alteración por respuestas mal reguladas debidas a la infección, puede desencadenar la eliminación no programada de células clave en la inmunidad, lo que generaría una parálisis inmune de consecuencias fatales. A pesar de los avances descritos, aún queda por descubrir otras vías moleculares que ayuden a comprender, de manera holística, la fisiopatología de la sepsis y permitan buscar opciones terapéuticas dirigidas a daños específicos para contribuir al tratamiento y disminución de la mortalidad.

Exención de responsabilidad: Los autores confirman que el contenido clínico, diagnóstico y terapéutico del reporte de caso son producto del escrutinio médico aplicado al paciente y son responsabilidad estrictamente de los profesionales involucrados en la publicación de este reporte de caso.

Contribución de los autores: Pablo Andrés Vélez, Evelyn Elizabeth Castro, Mario Montalvo, Santiago Aguayo, Gustavo Velarde y Fernando E. Jara han participado en la concepción y diseño del artículo, recolección de resultados, análisis e interpretación de datos, redacción del artículo, revisión crítica del artículo, aprobación de la versión final, convocatoria de pacientes y aporte de material de estudio. Jorge Luis Vélez ha participado en la concepción y diseño del artículo, análisis e interpretación de datos, redacción del artículo, revisión crítica del artículo, aprobación de la versión final, convocatoria de pacientes y aporte de material de estudio.

Fuentes de financiamiento: Este artículo ha sido financiado por los autores.

Conflictos de interés: Los autores declaran no tener ningún conflicto de intereses.

\section{REFERENCIAS BIBLIOGRÁFICAS}

1. Singer M, Deutschman CS, Seymour CW, Shankar-Hari M, Annane D, Bauer $M$, et al. The Third International Consensus Definitions for Sepsis and Septic Shock (Sepsis-3). JAMA. 2016; 315(8): 801-10.

2. Cao C, Yu M, Chai Y. Pathological alteration and therapeutic implications of sepsis-induced immune cell apoptosis. Cell Death Dis. 2019; 10(10): 782.

3. Pinheiro da Silva F, Nizet V. Cell death during sepsis: integration of disintegration in the inflammatory response to overwhelming infection. Apoptosis. 2009; 14(4): 509-21.

4. Hattori Y, Takano K, Teramae H, Yamamoto S, Yokoo H, Matsuda $\mathrm{N}$. Insights into sepsis therapeutic design based on the apoptotic death pathway. J Pharmacol Sci. 2010; 114(4): 354-65.

5. Mitchell R, Kumar V, Abbas A, Aster J. Robbins y Cotran - Patología estructural y funcional. 9na. Barcelona, España: Elsevier; 2017.

6. Cohen JJ, Duke RC, Fadok VA, Sellins KS. Apoptosis and programmed cell death in immunity. Annu Rev Immunol. 199; 10: 267-93.

7. Girardot T, Rimmelé T, Venet F, Monneret G. Apoptosis-induced lymphopenia in sepsis and other severe injuries. Apoptosis Int J
Program Cell Death. 2017; 22(2): 295-305.

8. Wesche DE, Lomas-neira JL, Perl M, Chung C, Ayala A. Leukocyte apoptosis and its significance in sepsis and shock. J Leukoc Biol. 2005; 78(2): 325-37.

9. Sun H, Gong S, Carmody RJ, Hilliard A, Li L, Sun J, et al. TIPE2, a negative regulator of innate and adaptive immunity that maintains immune homeostasis. Cell. 2018; 133(3): 415-26.

10. Bravo R, Gutierrez T, Paredes F, Gatica D, Rodriguez AE, Pedrozo $Z$, et al. Endoplasmic reticulum: ER stress regulates mitochondrial bioenergetics. Int J Biochem Cell Biol. 2012; 44(1): 16-20.

11. Zhu X, Yao F, Yao Y, Dong N, Yu Y, Sheng Z. Endoplasmic reticulum stress and its regulator XBP-1 contributes to dendritic cell maturation and activation induced by high mobility group box-1 protein. Int J Biochem Cell Biol. 2012; 44(7): 1097-105.

12. Ravichandran KS. Beginnings of a good apoptotic meal: the find-me and eat-me signaling pathways. Immunity. 2011; 35(4): 445-55.

13. Ravichandran KS. Find-me and eat-me signals in apoptotic cell clearance: progress and conundrums. J Exp Med. 2010; 207(9): 1807-17.

14. Cheng Y, Marion TN, Cao X, Wang W, Cao Y. Park 7: ANovel Therapeutic Target for Macrophages in Sepsis-Induced Immunosuppression. Front Immunol. 2018; 9: 2632.

15. Zeerleder S, Zwart B, Wuillemin WA, Aarden LA, Groeneveld $\mathrm{ABJ}$, Caliezi $\mathrm{C}$, et al. Elevated nucleosome levels in systemic inflammation and sepsis. Crit Care. 2003; 31(7):1947-51.

16. Lang JD, Matute-Bello G. Lymphocytes, apoptosis and sepsis: making the jump from mice to humans. Crit Care. 2009;13(1):109.

17. Alves-Filho JC, Spiller F, Cunha FQ. Neutrophil paralysis in sepsis. Shock. 2010; 34(Suppl. 1): 15-21.

18. Martins S de T, Silveira GF, Alves LR, dos Santos CND, Bordignon J. Dendritic Cell Apoptosis and the Pathogenesis of Dengue. Viruses. 2012; 4(11): 2736-53.

19. Koçkara A, Kayataș M. Renal cell apoptosis and new treatment options in sepsis-induced acute kidney injury. Ren Fail. 2013; 35(2): 291-4.

20. Moulding DA, Akgul C, Derouet M, White MR, Edwards SW. BCL2 family expression in human neutrophils during delayed and accelerated apoptosis. J Leukoc Biol. 2011; 70(5): 783-92.

21. Milot E, Filep JG. Regulation of neutrophil survival/apoptosis by Mcl-1. Scie World J. 2011; 11: 1948-62.

22. Mica L, Härter L, Trentz O, Keel M. Endotoxin reduces CD95-induced neutrophil apoptosis by cIAP-2-mediated caspase-3 degradation. J Am Coll Surg. 2004; 199(4): 595-602.

23. Derouet M, Thomas L, Moulding DA, Akgul C, Cross A, Moots RJ, et al. Sodium salicylate promotes neutrophil apoptosis by stimulating caspase-dependent turnover of Mcl-1. J Immunol (Baltim Md 1950). 2006; 176(2): 957-65.

24. Luan Y-Y, Dong N, Xie M, Xiao X-Z, Yao Y-M. The significance and regulatory mechanisms of innate immune cells in the development of sepsis. J Interferon Cytokine Res. 2014; 34(1): 2-15.

25. Sica A, Mantovani A. Macrophage plasticity and polarization: in vivo veritas. J Clin Invest. 2012; 122(3): 787-95.

26. Zhu X-M, Yao Y-M, Liang H-P, Liu F, Dong N, Yu Y, et al. Effect of high mobility group box-1 protein on apoptosis of peritoneal macrophages. Arch Biochem Biophys. 2009; 492(1-2): 54-61.

27. Zheng D, Sun Q, Su Z, Kong F, Shi X, Tong J, et al. Enhancing specific-antibody production to the $\operatorname{ragB}$ vaccine with GITRL that expand Tfh, IFN- $\gamma(+)$ T cells and attenuates Porphyromonas gingivalis infection in mice. PloS One. 2013; 8(4): e59604.

28. Granucci F, Zanoni I. El ciclo de vida de las células dendríticas. Cell Cycle. 2009; 8(23): 3816-21.

29. Granucci F, Zanoni I, Ricciardi-Castagnoli P. Papel central de las células dendríticas en la regulación y desregulación de las respuestas inmunes. Cell Mol Life Sci. 2008; 65(11): 1683-97.

30. Gautier EL, Huby T, Saint-Charles F, Ouzilleau B, Chapman MJ, Lesnik 
P. Enhanced dendritic cell survival attenuates lipopolysaccharideinduced immunosuppression and increases resistance to lethal endotoxic shock. J Immunol (Baltim Md 1950). 2008; 180(10): 6941-6.

31. Tinsley KW, Grayson MH, Swanson PE, Drewry AM, Chang KC, Karl IE, et al. Sepsis induces apoptosis and profound depletion of splenic interdigitating and follicular dendritic cells. J Immunol (Baltim Md 1950). 2003; 171(2): 909-14.

32. Mauri C, Bosma A. Immune regulatory function of B cells. Annu Rev Immunol. 2012; 30: 221-41.

33. Rawlings DJ, Schwartz MA, Jackson SW, Meyer-Bahlburg A. Integration of B cell responses through Toll-like receptors and antigen receptors. Nat Rev Immunol. 2012; 12(4): 282-94.

34. Brinkhoff A, Zeng Y, Sieberichs A, Dolff S, Shilei X, Sun M, et al. B-cell dynamics during experimental endotoxemia in humans. Biosci Rep. 2019; 39(5).

35. Deng Q, Zhao T, Pan B, Dennahy IS, Duan X, Williams AM, et al. Protective effect of tubastatin a in CLP-induced lethal sepsis. Inflammation. 2018; 41(6): 2101-9.

36. Forel J-M, Chiche L, Thomas G, Mancini J, Farnarier C, Cognet C, et al. Phenotype and functions of natural killer cells in critically-ill septic patients. PloS One. 2012; 7(12): e50446.

37. Venet F, Davin F, Guignant C, Larue A, Cazalis M-A, Darbon R, et al. Early assessment of leukocyte alterations at diagnosis of septic shock. Shock. 2010; 34(4): 358-63.

38. Holub M, Klucková Z, Helcl M, Príhodov J, Rokyta R, Beran 0. Lymphocyte subset numbers depend on the bacterial origin of sepsis. Clin Microbiol Infect Dis. 2003; 9(3): 202-11.

39. Souza-Fonseca-Guimaraes F, Parlato M, Philippart F, Misset B, Cavaillon J-M, Adib-Conquy $M$, et al. Toll-like receptors expression and interferon- $\gamma$ production by NK cells in human sepsis. Crit Care. 2012; 16(5): R206.

40. Halstead ES, Carcillo JA, Schilling B, Greiner RJ, Whiteside TL. Reduced frequency of CD56 dim CD16 pos natural killer cells in pediatric systemic inflammatory response syndrome/sepsis patients. Pediatr Res. 2013; 74(4): 427-32.

41. Inoue S, Unsinger J, Davis CG, Muenzer JT, Ferguson TA, Chang K, et al. IL-15 prevents apoptosis, reverses innate and adaptive immune dysfunction, and improves survival in sepsis. J Immunol (Baltim Md 1950). 2010; 184(3): 1401-9.

42. Limaye AP, Kirby KA, Rubenfeld GD, Leisenring WM, Bulger $E M$, Neff $M J$, et al. Cytomegalovirus reactivation in critically ill immunocompetent patients. JAMA. 2008; 300(4): 413-22.

43. Hsu J, Hodgins JJ, Marathe M, Nicolai CJ, Bourgeois-Daigneault M-C, Trevino TN, et al. Contribution of NK cells to immunotherapy mediated by PD-1/PD-L1 blockade. J Clin Invest. 2018; 128(10): 4654-68.

44. Patil NK, Guo Y, Luan L, Sherwood ER. Targeting immune cell checkpoints during sepsis. Int J Mol Sci. 2017; 18(11).

45. Abbas, Lichtman, Pillai. Inmunología celular y molecular. 9na ed. España: Elsevier; 2018.

46. Booth JS, Toapanta FR, Salerno-Goncalves R, Patil S, Kader HA Safta $A M$, et al. Characterization and functional properties of gastric tissue-resident memory $T$ Cells from children, adults, and the elderly. Front Immunol. 2014; 5.

47. Bevan MJ. Memory T cells as an occupying force. Eur J Immunol. 2011; 41(5): 1192-5.

48. Cabrera-Perez J, Condotta SA, Badovinac VP, Griffith TS. Impact of sepsis on CD4 T cell immunity. J Leukoc Biol. 2014; 96(5): 767-77.

49. Ma T, Han L, Gao Y, Li L, Shang X, Hu W, et al. The endoplasmic reticulum stress-mediated apoptosis signal pathway is involved in sepsis-induced abnormal lymphocyte apoptosis. Eur Surg Res. 2008; 41(2): 219-25.

50. Weber SU, Schewe J-C, Lehmann LE, Müller S, Book M, Klaschik S,

et al. Induction of Bim and Bid gene expression during accelerated apoptosis in severe sepsis. Crit Care. 2008; 12(5): R128.

51. Hotchkiss RS, Swanson PE, Knudson CM, Chang KC, Cobb JP, Osborne $\mathrm{DF}$, et al. Overexpression of $\mathrm{Bcl}-2$ in transgenic mice decreases apoptosis and improves survival in sepsis. J Immunol (Baltim MC 1950). 1999; 162(7): 4148-56.

52. Gurung P, Rai D, Condotta SA, Babcock JC, Badovinac VP, Griffith TS. Immune unresponsiveness to secondary heterologous bacterial infection after sepsis induction is TRAIL dependent. J Immunol (Baltim Md 1950). 2011; 187(5): 2148-54.

53. Unsinger J, Kazama H, MCDonough JS, Griffith TS, Hotchkiss RS, Ferguson TA. Sepsis-induced apoptosis leads to active suppression of delayed-type hypersensitivity by $\mathrm{CD} 8+$ regulatory $T$ cells through a TRAIL-dependent mechanism. J Immunol (Baltim Md 1950). 2010; 184(1): 6766-72.

54. Chang KC, Unsinger J, Davis CG, Schwulst SJ, Muenzer JT, Strasser $A$, et al. Multiple triggers of cell death in sepsis: death receptor and mitochondrial-mediated apoptosis. FASEB J Off Publ Fed Am Soc Exp Biol. 2007; 21(3): 708-19.

\section{Correspondencia:}

Pablo Andrés Vélez Páez

Dirección: Facultad de Ciencias Médicas - Universidad Central del Ecuador Iquique N14-121 y Sodiro - Itchimbía. El Dorado, Ecuador.

Teléfono: (593-02) 2528690

Correo electrónico: pablomh2586@gmail.com

Recibido: 14 de abril de 2020 Evaluado: 10 de mayo de 2020 Aprobado: 24 de mayo de 2020

(c) La revista. Publicado por Universidad de San Martín de Porres, Perú. (cc) $\mathbf{B Y}$ Licencia de Creative Commons Artículo en acceso abierto bajo términos de Licencia Creative Commons Atribución 4.0 Internacional. (http://creativecommons.org/licenses/by/4.0/)

\section{ORCID iDs}

Pablo Andrés Vélez

Evelyn Elizabeth Castro

Mario Montalvo

Santiago Aguayo

Gustavo Velarde

Fernando E. Jara González

Jorge Luis Vélez
Th https: / / orcid.org/0000-0002-6392-3895
https: / / orcid.org/0000-0002-9577-613X
https: / / orcid.org/0000-0003-2987-7095
https: / / orcid.org/0000-0003-4919-5497
https: / / orcid.org/0000-0002-6530-1280
https: / / orcid.org/0000-0003-2132-7187
https: / / orcid.org/0000-0002-6956-4475 